\title{
O BRAVO REI, A TERRA E OS CLÉRIGOS: LEIS DE DESAMORTIZAÇÃO E AÇÃO GRACIOSA DE D. AFONSO IV (1325-1357)
}

\section{THE BRAVE KING, THE LAND AND THE CLERGYMEN: LAWS AGAINST THE CLERGY'S OWNER SHIP OF LAND AND RESOURCES AND THE GRACEFUL ACTION OF AFONSO IV OF PORTUGAL (1325-1357)}

\begin{abstract}
Resumo: $O$ presente artigo tem por objetivo analisar como o rei D. Afonso IV aplicou a lei de desamortização em Portugal durante o seu reinado de trinta e dois anos. A lei de desamortização foi publicada por seu pai, D. Dinis, nos anos 1280, tendo por objetivo impedir que clérigos, mosteiros ou igrejas tivessem acesso a doações ou a heranças de terra no reino, evitando a alienação de vastas porções destas que, doravante, pertenceriam à Igreja. Contudo, por várias vezes, D. Afonso IV suspendeu a aplicação desta lei em relação aos clérigos durante seu reinado através de sua ação graciosa. Acreditamos que tal suspensão ocorreu posto que ao rei cabia exercer, principalmente, a justiça e muitos clérigos ou instituições clericais que o peticionavam eram pobres e incapazes de se sustentarem, justificando, assim, a suspensão da lei. Além disso, ao criar a imagem de si mesmo como um rei justo, preocupado com o bem-estar de seus súditos e preparado para suspender a letra da lei em nome do bem comum, Afonso IV fortalecia seu próprio poder como condutor-mor do nascente Estado Português frente aos grupos poderosos que favoreciam um reino com um poder régio mais enfraquecido, como os grandes prelados e os nobres.
\end{abstract}

Palavras-Chaves: Lei de desamortização. D. Dinis. D. Afonso IV. clérigos.

Abstract: The following article has as it's objective to analyze how the king Alfonso IV put the law that abolished monasteries and Other religious institutions the right to have goods and resources of their own to work in his Kingdom of Portugal during his reign of 32 years. These laws had been published by his father, the king Dinis, in the Years 1280's and had as it's main objective to not alienate large tracts of resources, like lands, in the hands of the Church. However Alfonso IV, due to a number of reasons, suspended their application through his gracious action. We firmly believe that was made because it was the king's most important role to exercise justice and

\footnotetext{
${ }^{1}$ Mestrando do Programa de Pós -Graduação em História (PPGH) da Universidade Federal Fluminense, UFF, orientado pela Prof. ${ }^{a}$ Dr. $^{a}$ Vânia Leite Fróes com o projeto de pesquisa sobre a Boa-Governança em Portugal no século XIV em relação aos clérigos durante o reinado de D. Afonso IV e analisando o pensamento político de D. Álvaro Pais.
} 
Revista da Seção Judiciária do Rio de Janeiro

many of the clergymen and institutions that petitioned were poor and thusunable to survive, what justified the suspension of the law. Beyond that, by creating animage of himself as a just king, worried with his subjects and that was prepared to suspend the law for the sake of the common good, Alfonso would strengthen his own power as the main leader of the Portuguese state then in the making, against other powerful groups in society that favored a weakened royal power, like the great prelates and the nobility.

Keywords: Abolition Laws. King Dinis. King Alfonso IV. Clergymen.

Recebido em: 27/09/2021 Aceito para publicação em: 29/11/2021 
Revista da Seção Judiciária do Rio de Janeiro

\section{INTRODUÇÃO}

A Idade Média Tardia (c. 1250 - c.1520), estendendo-se por mais de dois séculos e um período bastante rico da História europeia, é um terreno privilegiado para o historiador se dedicar a numerosos temas. Com efeito, se estes séculos foram marcados por sucessivas crises como as fomes, as guerras e os surtos de peste, começando com o grande surto de 1348 a 1352, que dificultavam a vida, também foram marcados por muitas continuidades em relação aos séculos anteriores ${ }^{2}$, levando a reconsiderarmos a ideia de Huizinga ${ }^{3}$ de que fosse apenas uma época de crise, na qual, lentamente, se via o fim de uma era e o desabrochar de uma outra, a modernidade, sobre suas ruínas. Aspectos da vida como a devoção laica, o fortalecimento e a ascensão definitiva das cidades $^{4}$, os debates intelectuais e filosóficos ${ }^{5}$, todos permaneceram inalterados ao longo deste período, garantindo que, com isso, a sociedade cristã medieval não se dissolvesse simplesmente no ar, mas sim sobrevivesse ainda que com transformações.

Dentre estes temas, um dos que mais manteve continuidades foi aquele da ascensão do Estado. Apesar de que possa parecer polêmica a ideia do surgimento do Estado Moderno na Idade Média, já há algum tempo parece haver um consenso, ao menos entre os estudiosos da política medieval, de que isto foi de fato uma realidade, com muitos aparelhos estatais surgindo, numa longa duração, entre os séculos XIII e o XV', de modo que se poderia, sim, situar o nascimento do Estado na Idade Média ao longo dos seus últimos trezentos anos. Dentre as exceções, podemos

\footnotetext{
${ }^{2}$ BASCHET, Jérôme. Primeira Parte: Formação e desenvolvimento da Cristandade feudal - Da Europa Medieval à América Colonial. In: BASCHET, Jérôme. A Civilização Feudal: Do ano mil à Colonização da América. São Paulo: Editora Globo, 2005. p. 247-274.

${ }^{3}$ HUIZINGA, Johan. O Outono da Idade Média. São Paulo: Cosac \& Naify Editora, 2010.

${ }^{4}$ BOWSKY, William. A Mediaeval Italian Commune: Siena under the Nine, 1287-1355. Berkeley: University of California Press, 1981.

${ }^{5}$ BOEHNER, Philotheus; GILSON, Étienne. História da Filosofia Cristã. Petrópolis: Editora Vozes, 2017.

${ }^{6}$ GUENÉE, Bernard. L'Ocident aux XIV et XV siècles: Les États. Paris: Presse Universitaire de France, 1971.; HARDING, Alan. Medieval Law and the foundation of the State. Oxford: Oxford University Press, 2005.
} 
Revista da Seção Judiciária do Rio de Janeiro

contar o trabalho de Jérôme Baschet, que, seguindo os modelos de discussão de Bourdieu, defendeu em seu manual, A Civilização Feudal: do ano mil à colonização da América', que não haveria formação do Estado na Idade Média ${ }^{8}$, embora ao longo destes últimos trezentos anos, a monarquia veria o seu poder se fortalecer. Concordamos com a primeira posição por entender que, apesar de, de fato, não ter havido um pleno monopólio da violência no período medieval, condição fundamental para o surgimento do Estado, de acordo com Baschet, apoiado em Bourdieu, ainda assim, o rei buscou afirmá-lo e construí-lo, de modo a garantir o bem-comum. No mundo medieval, isto seria garantir que a sociedade laica tivesse a melhor vida possível e que fossem mantidas a paz e a justiça de modo a auxiliar na salvação dos súditos. Para tanto, esta afirmação e construção por parte do poder régio pautou-se pela promulgação de leis, pela construção de uma burocracia, e, já mais tarde, a partir do século $\mathrm{XV}$, pela formação de um exército regular.

Logo, este artigo tem por objetivo analisar um aspecto específico deste desenvolvimento estatal ao longo da Baixa Idade Média no reino de Portugal: aquele da relação entre os clérigos e o rei desde a legislação de desamortização e de como, a partir das decisões régias em aplicá-la ou não, o próprio papel do rei se fortalecia e se legitimava frente aos súditos, no reino mais a extremo do oeste da Cristandade.

Buscaremos, ainda, nos concentrar no reinado de D. Afonso IV(1325-1357) que, como a historiografia mais recente vem assinalando, foi um monarca fundamental na construção deste aparelho estatal em Portugal ${ }^{9}$, ideia da qual compartilhamos.

Iniciaremos o percurso analisando qual foi o propósito da criação destas leis pelo pai de nosso monarca, D. Dinis (1279-1325). Após isto, a partir de documentos preservados em sua chancelaria, veremos como D. Afonso IV efetivamente as

\footnotetext{
${ }^{7}$ Cf. BASCHET, (2005).

${ }^{8}$ Ibid., p. 263-269.

${ }^{9}$ HOMEM, Luís Armando Carvalho. Dionisus et Alfonsus, Dei Gratia Reges et communis utilitatis Gratia legiferi. Revista de História da Faculdade de Letras da Universidade do Porto, Porto, v. 11, p. 11-111, 1994. Disponível em: https://ojs.letras.up.pt/index.php/historia/article/view/5660. Acesso em: 1 dez. 2021.;VASCONCELOS E SOUSA, Bernardo. D. Afonso IV. Lisboa: Temas \& Debates, 2009.
} 
Revista da Seção Judiciária do Rio de Janeiro

aplicou. Por fim, veremos qual era o objetivo do monarca com sua ação em relação a elas.

Este trabalho, portanto, se encontra na área de uma História Política Renovada $^{10}$ - área marcada pela relação das preocupações típicas da História Política, como o estudo das instituições e das ações dos grandes personagens, com outros aspectos da vida passada das sociedades humanas, como o Direito, as ideias, a cultura, dentre outros. A História política renovada além disso, ainda pode ser um centro estratégico para a disciplina histórica como um todo, como assinalou Jacques Le Goff, o que torna o seu estudo ainda mais estimulante ${ }^{11}$.

Neste artigo em específico, nossa principal relação será com as histórias do Direito e a social, já que, ao mesmo tempo em que analisa a atividade legislativa, se relaciona a um importante grupo da sociedade medieval: os clérigos.

\section{D. DINIS E A DESAMORTIZAÇÃO}

Reinando entre 1279 e 1325 e sendo o pai de D. Afonso IV, D. Dinis foi um dos grandes responsáveis em Portugal pelo desenvolvimento do Estado. Legou ao reino numerosas leis importantes no nível estrutural. De fato, seu reinado foi marcado pelo desenvolvimento de instituições como a marinha, os corregedores e a universidade e pela realização de inquirições demonstrando a força do poder régio nestes fins de século XIII e inícios do século XIV e bases de um futuro Estado ${ }^{12}$.

Uma das áreas nas quais D. Dinis interveio desde cedo foi aquela da Igreja. Em Portugal, esta sempre tivera, simultaneamente, relações de apoio e de conflitos com a monarquia. Aquelas surgiam devido à necessidade da Igreja em obter o apoio

10 BARROS, José d'Assunção. História política: da expansão conceitual às novas conexões intradisciplinares. Revista OPSIS, Goiânia, v. 12, n. 1, p. 29-55, jan./jun. 2012. Disponível em: https://revistas.ufg.br/Opsis/article/view/17338. Acesso em: 2 dez. 2021.

11 LE GOFF, Jacques. Seria o político ainda a ossatura da História? In: LE GOFF, Jacques. 0 maravilhoso e o quotidiano na Idade Média. Lisboa: edições 70, 1981. p. 221-243.

${ }_{12}$ PIZARRO, José Augusto Sotto Mayor. D. Dinis: Um gênio da Política. Lisboa: Temas \& Debates, 2012. p. 329-335. 
Revista da Seção Judiciária do Rio de Janeiro

do poder régio para defendê-la dos inimigos, nomeadamente os mouros, e dos abusos dos grandes ao mesmo tempo em que, por sua vez, havia a necessidade da jovem monarquia de ter o seu poder legitimado como algo querido por Deus ${ }^{13}$. Já as de conflitos surgiam do fato do poder régio ver na Igreja algo que tolhia suas pretensões de domínio sobre todo o território e esta, por sua vez, não desejar perder suas liberdades eclesiásticas e suas jurisdições sobre seus numerosos coutos ${ }^{14}$.

Estes conflitos já haviam estado a rubro antes, durante a história da monarquia. Em inícios do século XIII, D. Afonso II, avô de D. Dinis, era excomungado pelo papa por tentar limitar o poder da Igreja através de suas leis. Seu tio, D. Sancho II, também fora excomungado e deposto na metade do século, tanto por não respeitar os direitos da Igreja quanto pelo estado de anarquia em que o reino, durante seu reinado, imergiu. Por sua vez, isto deixou vago o trono para seu pai, D. Afonso III, que, embora tenha tido sucesso na pacificação do reino e na sua transmissão ao filho, não teve o mesmo sucesso no que concerne às questões eclesiásticas, que continuavam a preponderar ${ }^{15}$. Tornava-se, assim, urgente que o rei conseguisse um acordo com o papado de modo a ter sucesso em seu reinado e no seu plano de governo.

A solução passou por assinatura de uma série de concordatas, nas quais, a priori, o rei e a Igreja delimitavam melhor cada um os seus direitos e deveres. Longe de serem pacíficas, as concordatas suscitaram também numerosas polêmicas ${ }^{16}$. Não obstante, elas tiveram sucesso em tirar o reino do interdito, situação na qual estava quando da morte de Afonso III, e em normalizar as relações entre o reino de Portugal e a Santa Sé. Contudo, a legislação dionisina não terminou por aí e

\footnotetext{
${ }^{13}$ MATTOSO, José. Identificação de um país: Ensaio sobre as origens de Portugal (1096-1325) Oposição/Composição. Lisboa: Editora Temas e Debates, 2016. p. 723-739.

${ }_{14}$ MATTOSO, José (org.). História de Portugal: A Monarquia Feudal 1096-1480. Lisboa: Editorial Estampa, 1997. p. 100. vol. 2.

${ }^{15}$ VENTURA, Leontina. D. Afonso III. Lisboa: Editora Temas \& Debates, 2009.

16 MENEZES LUIZ, Láisson. As Concordatas: abusos e violências cometidas contra os clérigos em Portugal ao tempo de D. Dinis. Revista Sapiência: Sociedades, Saberes e Práticas Educacionais, Iporá, v. 1, n. 2, p. 58-72, jul./dez. 2012. Disponível em: https://www.revista.ueg.br/index.php/sapiencia/article/view/2688. Acesso em: 30 nov. 2021.
} 
Revista da Seção Judiciária do Rio de Janeiro

prosseguiu em sua busca para melhor controlar e domesticar os clérigos. Aproveitando-se das fraquezas do papado de fins do século XIII e do aumento do seu poder interno, D. Dinis optou justamente por promulgar estas leis de desamortização.

Convém esclarecer que, para as analisarmos, usaremos as compilações das Ordenações do rei D. Duarte, organizadas em edição recente por Martim de Albuquerque e Eduardo Nunes ${ }^{17}$. Se, por um lado, a presença desta legislação numa compilação do século XV demonstra sua importância para o reino, por outro, sabemos que não é o mesmo que se analisar diretamente o texto dionisino do fim do século XIII. Contudo, sabendo ser o rei D. Duarte um homem culto e erudito, duvidamos que haja qualquer discrepância entre os dois textos.

Passemos agora à análise.

Sob o ponto de vista metodológico, observaremos o método de Laurence Bardin e enunciado por Ciro Flamarion e Ronaldo Vainfas, em seu livro, Domínios da História $^{18}$. Faremos, portanto, uma análise semântica dos documentos, analisando quais foram as palavras-chave usadas pelo rei e qual foi o tema dos mesmos, para demonstrar o objetivo de sua legislação e como buscava justificá-la. A primeira lei de desamortização foi promulgada em 1286, estando o rei em Lisboa. Seu teor segue abaixo:

Don denis E cetera. A todo-llos allcaydes meirinhos Comendadores Juizes $\mathrm{E}$ Justiças/ E almoxarifes ./ E tabaliãaes de meus Reinos saúde sabede que os Reis que ante mym foram defenderam que ordeens nem creligos nom comprassen herdamentos em seu Reino./ E outros o defendo eu./ $E$ ora alguns conçelhos(1)xe me enujaron queixar que creligos $E$ ordeens faziam muy grandes compras em minha terra. $\mathrm{E}$ que esto era meu exerdamento./ $\mathrm{E}$ muy grande dapnodelles de guisa que quando os eu $\mathrm{E}$ os caualeiros da minha Corte./ E os concelhos ouuese mester pera meu serviço que me nom poderiam seruirasy como deuiam $E$ eu asy entendo $E$ soo maravilhado como samtan ousados de comprar os herdamentos contra o nosso defendimento $E$

\footnotetext{
${ }^{17}$ ALBUQUERQUE, Martim de; NUNES, Eduardo Borges (org.). Ordenações Del-Rei Dom Duarte. Lisboa: Fundação Calouste Gulbenkian, 1988.

${ }^{18}$ CARDOSO, Ciro Flamarion; VAINFAS, Ronaldo. História e análise de textos. In: CARDOSO, Ciro Flamarion; VAINFAS, Ronaldo (org.). Domínios da História: Ensaios de teoria e metodologia. Rio de Janeiro: Editora Campus, 1997. p. 536-567.
} 


\begin{abstract}
Porem mando e defendo que ordeens nem crelligos nom comprem herdamentos/E aquelles herdamentos que comprarem ou fezerem comprar ataa'qui pera sydes que eu fuy Rey dou-lhes prazo que o uendam desta santa Maria/ d'agosta tahuum ano./ E se os non uenderem taa a este prazo perca'-nas./ E estocatade ora uos que nomrreçeba eu hi engano nem as façam uendidiças $E$ fiquem eles com ellas./ $E$ em outra guisa uos me lazeraredes./ E uos tabaliaães se per uoseunom for desenganado de todo. /E per uosnom souber os que ficam que as nomuendenmdes que aquell prazo passar morreredesporem./(....) (Ordenações Del-Rei D. Duarte. f.90)
\end{abstract}

Destarte, o rei proibia categoricamente que os sacerdotes, os mosteiros e as igrejas paroquiais tivessem bens. O monarca dava um prazo para que as propriedades adquiridas até aquele momento fossem vendidas, sem maiores punições para clérigos e responsabilizava seus oficiais régios para que isto fosse levado a cabo. Com isto, a lei pretende diminuir o poder clerical frente ao régio e impedir a aquisição de mais terras pela Igreja no reino de Portugal. Isto era um problema sério: ao adquirir as terras, estas ficavam imunes à justiça régia, pois a Igreja entendia que elas passavam imediatamente a ficar sob a alçada do direito canônico, que, como demonstrou Fossier, pretendia ser, durante os séculos XII, XIII e mesmo na primeira metade do XIV, uma lei que submetia tanto clérigos quanto leigos ${ }^{19}$.

Ao que tudo indica este também era o entendimento de D. Dinis, de modo que a esta lei, localizada no verso do seu fólio 90 , se seguiu outra ordenando aos clérigos a venda das terras que possuíam de modo bem direto e uma outra ainda que impedia os nobres de legarem bens pios às instituições eclesiásticas, como podemos ver abaixo:

Dom Denis $E$ cetera onde como sobre a ley que fezemos em rrazam dos bens dos filhos dalgo que morriam professos Em o Moesteiro em que entrauomrrecreçiam muitas duuedasdezendo os sagraees que se deuyam a entender doutra guisa./ $E$ porque os papas./ $E$ os enperadores./ $E$ os Reis

\footnotetext{
${ }^{19}$ FOSSIER, Arnaud-Vivien. La Pénitencerie pontificale en Avignon (XIV siècle) ou la justice des âmes comme style de gouvernement. Les Justices d'Église dans le Midi (XI-XV siècles): 42éme colloque de Fanjeaux, Fanjeaux, p. 199-240, jul. 2006. Disponível em: https://halshs.archives-ouvertes.fr/halshs-00369875. Acesso em: 30 nov. 2021.
} 


\begin{abstract}
que fazem as leis deuem declarar qual foyho entendimento que ouueram aas leis que fezeram . E por esso eu querendo tolher em essas duuedas que naçeram na ley susodita./ (95v) Outorgo $E$ declaro que tallfoy./ o entendimento meu $E$ he em rrazam dessa ley que as donas e as mulheres que Já eram em ordem quando aquella minha leyfoy feita se auyam alguns herdamentos ante dessa ley que os Moesteiros em que se entraronaJam esses herdamentos./ ou façam dellescomolhes mandar sa abadessa ou aquell que for seu mayor no Moesteiro.E quanto he dos herdamentos que ouueram depois dessa ley ou entenderem a auer de seuos padres./ ou de suas madres ou de seus parentes ou guaanharem ou poderem guaanhardalhur onde quiser./Porque se esses herdamentos ficassem aos moesteiros tornar-se-ya depois em meu desserviço./ E em grande dapno de meus Reinos per rrazam que os que laurassen em esses herdamentosnomhiriam em oste nem fariam a mym aquelles serviços que a mydeuem fazer pera defendimento de minha terra. Outrosy porque louado deus os Moesteiros que ora há em-na terra samrricos d'erdamentos./ E de possysoees de guisa que podem muy bem guarecer. Digo $E$ Decllaro que o meu entendimento foy e he que as donas $E$ as molheres $E$ caualeiros $E$ outros homens nomaJam os herdamentos epossysoees sobreditas nem os moesteiros em que os sobreditos entrarem senom em sua uyda. / E se os dar ou uender quiserem em sauyda a pessoas leigas posa'-nos fazer mas nom os posam dar nem alhear nem escambar nem transamudar per nehua maneira a moesteiro nem a ordem nem a pessoa outra senomsagrall. (...) (Ordenações Del-Rei D. Duarte, f.95/95 v.)
\end{abstract}

D. Dinis assim declarou as leis de desamortização com objetivo de impedir que terras e, portanto, pessoas fugissem à sua jurisdição, o que mostra bem como, neste primeiro momento da construção do Estado em Portugal, os ideais feudais ainda são preponderantes. Aquele que domina a terra domina os homens. Assim sendo, o rei não pode se dar ao luxo de perder o controle sobre estas, ainda mais se estivermos falando de largos pedaços de terra que já são, por si só, dominados pela nobreza e pelo clero, sobretudo no Norte, zona mais populosa do país ${ }^{20}$.

Possuindo o apoio de uma ordem institucional mais organizada e com numerosos conselheiros legistas, muitos deles seus clérigos, D. Dinis, ainda se usando sobretudo desta lógica feudal, vai formando e consolidando seu poder. Diferente, no entanto, será a atitude de seu filho e a maneira como este demonstrará seu poder sobre os clérigos.

${ }^{20}$ Ibid., p. 204-206.

Revista Auditorium, Rio de Janeiro, v. 25, n. 53, p. 104-130, nov. 2021/fev. 2022 
Revista da Seção Judiciária do Rio de Janeiro

\section{D. AFONSO IV E A APLICAÇÃO DA LEI EM SUA ÉPOCA}

Em 1325, morre D. Dinis. Em seu lugar, assume seu filho que reinou com o nome de D. Afonso IV. No início, pensou-se que D. Afonso, no vigor da idade, com 34 anos ao assumir o trono, se posicionaria contra a política de afirmação da autoridade régia promovida pelo seu pai, já que, de 1319 a 1324, se envolverá em séria guerra civil contra o progenitor ${ }^{21}$. No entanto, o que aconteceu foi justamente o contrário e, ao longo de seu longo reinado, D. Afonso IV se dedicou a fortalecer as políticas iniciadas pelo seu pai, levando o reino português ainda a mais inovações e aprofundamento do Estado nascente.

Tendo merecido duas biografias, uma por Bernardo Vasconcelos e Sousa, e outra menor, mas nem por isso sem valor, por Julieta Araújo22, D. Afonso IV foi responsável por criar ou aprofundar uma série de instituições importantes. Em sua época, surgiram os vereadores, existentes até hoje no mundo lusófono, os juízes de fora, o escrivão da puridade, espécie de primeiro secretário do rei de Portugal. Ainda nesse período, deu-se regimento aos corregedores que, tendo surgido na época de D. Dinis, eram fundamentais como olheiros e inspetores gerais do governo central nas localidades. Também em matéria legislativa, destacou-se produzindo - como ressaltou Armando Luís Carvalho Homem ${ }^{23}$ - uma grande quantidade de leis processuais, como se pode ver na edição crítica das Ordenações Del-Rei Dom Duarte preparada por Martim de Albuquerque e Eduardo Nunes, presentes nas páginas 311 a 340 da atual edição. Destacamos suas constantes leis para tentar regular o comportamento da nobreza e para tentar domesticar, em alguns aspectos, a classe clerical, como observamos nas leis contra os homizios e naquela que impedia a possibilidade de os clérigos advogarem e terem conhecimento dos testamentos dos

\footnotetext{
${ }^{21}$ Ibid., p. $139-141$.

22 ARAÚJO, Julieta. D. Afonso IV. In: MENDONÇA, Manuela. História dos Reis de Portugal: Da fundação à perda da Independência. Lisboa: Edições Quidnovi, 2010, p. 299-341. vol. 1.

${ }^{23}$ Ibid., p. 11-111.
} 
Revista da Seção Judiciária do Rio de Janeiro

leigos para além das diretrizes pias que estes pudessem vir a assinalar em suas últimas vontades.

Nascido no final do século XIII, D. Afonso IV é um homem tanto deste século quanto do século seguinte e, assim sendo, carrega em si tanto o legado do século anterior, marcado, como bem demonstrou Léopold Genicot, pela expansão do Ocidente em todas as esferas, inclusive na do desenvolvimento político ${ }^{24}$, como também as questões do século XIV, no qual viveu majoritariamente. Século, como já vimos, marcado pela crise e pela continuidade em vários aspectos da vida, dentre eles, o aumento do poder da monarquia e, portanto, do Estado.

Sentando-se no trono de uma Portugal que trazia em seu bojo grandes transformações suscitadas pelo pai, como a criação da universidade ${ }^{25}$, da primeira marinha de guerra, da diversificação das relações econômicas e do aumento da cidade de Lisboa, com a criação inclusive da Rua Nova, D. Afonso IV não poderia afirmar sua realeza apenas como um rei feudal comum. Homem inteligente, provavelmente, recebeu uma educação diferenciada para a época graças à cultura de seu pai, o novo monarca percebeu a necessidade de afirmar sua realeza para além do mundo feudal e começou a agir: criou os vereadores e os juízes de fora, extinguiu a vindicta privada, buscou garantir, o máximo possível, todas as jurisdições do reino em suas mãos, dentre outras ações.

Entretanto, isto não significa que o rei não tivesse uma personalidade diferente da do pai e é justamente na sua relação com as desamortizações que podemos melhor ver as diferenças entre as personalidades. Com efeito, ao contrário do rei-lavrador, D. Afonso IV, parece-nos, mostrou-se muito mais complacente com a aplicação das leis de desamortização.

${ }^{24}$ GENICOT, Léopold. Le XIII ${ }^{\mathbf{e}}$ siècle Européen. Paris: Presse Universitaire de France, 1984. p. 289-311.

${ }^{25}$ NASCIMENTO, Luciana de Araújo; COSTA, Célio Juvenal. A Singularidade da primeira Universidade Portuguesa no contexto do nascimento das universidades medievais. In: Seminário de Pesquisa do Programa de Pós-Graduação em Educação, Universidade Estadual de Maringá, 2011, Maringá. Anais [...]. Maringá: UEM, 2011. Disponível http://www.ppe.uem.br/publicacoes/seminario_ppe_2011/pdf/4/071.pdf. Acesso em: 2 dez. 2021. 
Revista da Seção Judiciária do Rio de Janeiro

Ao analisarmos os documentos de sua chancelaria - cujos três livros foram editados por A. H. Oliveira Marques nos anos 1980, pela Universidade Nova de Lisboa - demonstraremos os objetivos do rei e como este buscava legitimar seu poder, apoiado num determinado conceito de monarquia, lavrado pelos juristas. Igualmente, procuraremos ver como o grupo social dos clérigos se relacionava com o rei, a partir deste registro. Mais uma vez, esta demonstração será feita, pautando-se no método de Laurence Burdin ${ }^{26}$, dando ênfase, como no subitem anterior, às palavras-chave e temas do documento. Desta vez, também prestaremos atenção aos personagens, enunciados efetivamente, pela documentação.

Assim sendo, durante seu reinado, clérigos individuais aprenderam a procurar o rei para the pedir a graça de utilizarem terras herdadas para si e de ficarem com seus rendimentos, conforme podemos ver abaixo:

Dom Affonso pella graça de Deus rej de Portugal e do Algarve A uos meu almoxarife de Sanctarem e ao meu scriuan desse logo saúde. Sabede que Airas Dominguez clerigo Raçoeiro de sancta Maria de maruillamj disse que el há uinha no meu Regeengo das chantas que he em termho dessa uilla. A qual diz que ffoi de Garcia Perez da qual diz que pagou a mjn senpre os meus derectos assi como deuia. E diz que per razon do pregon que eu mandei dar polos meus Rejnos per razon da lej que el Rey Dom Afonso meu auoopos E outrossi el Rey Dom Denis meu padre em que defenderom que nenhuus clérigos nenordiijsnen filhos $d$ algo non conprassen nen guanhassen herdades regeengasnen foreiras e aqueles que as teuessen que ueessen a mjn mostrar como as auian segundo foj dado o dictopregon diz 0 dicto Airas Airas [sic] doimnguez que porque non veo ao tempo que per mjn foi mandado pera mostrar como auia a dicta vinha que lha filhaste per essa razon. E pediu mj por mercee que mjprouguesse de a teer e lhe mandasse entregar e que pagaria a mjn dela os derectos e foros que ende eu ej d auer. $\mathrm{E}$ eu ueendo o que mj pedia e querendo Ihj fazer graça e mercee tenho por ben e mando que el tenha e aia e possuya a dicta vinha em dias de ssavjda. E que a ssa morte a possa põer e leixar a hua pessoa lejga que seia tal deque eu possa auer os meus derectos e foros como deuo. E pagando el e a pessõa a que a leixar a mjn os dictos meus derectos e foros como deuo. E pagando el e a pessõa a que a leixar a mjn os dictos meus derectos e foros como deue. E mando a uos que Ihjalçedes o embargo que Ihj em ela posestes e que tha entreguedes. Vnde al non façades. e o dicto Airasdomiguez tenha esta carta e estolhj faço de graça. Dante em Lixbõa XVIIJ, dias de Setenbro. El Rei o mandou per Affonso esteuez seu ouujdor Francisco Lourenço a fez Era de M.iiijc. Lxxij. Anos. Affonso esteuez.

${ }^{26}$ Ibid., p. 536-576.

Revista Auditorium, Rio de Janeiro, v. 25, n. 53, p. 104-130, nov. 2021/fev. 2022 
Revista da Seção Judiciária do Rio de Janeiro

(Chancelarias portuguesas: Reinado de D. Afonso IV, Livro I, Livro de foros, documento 361)

Dessa forma, vemos aqui um exemplo destas petições, no qual um clérigo demanda ao rei que utilize a terra que - por acaso - está em sua posse. O rei decide que é por bem deixar que aquele se utilize dela, contanto que a deixe para um leigo ao morrer. Ambos, rei e clérigo, sabem que a letra exata da lei não está sendo cumprida e, por isto mesmo, o rei usa a expressão "que o está a fazer graça e mercê", ou seja, está decidindo a seu favor à revelia da lei. Estes tipos de petições individuais continuam a ser demandadas ao rei, como, por exemplo, constatamos com o caso do clérigo Miguel Eannes, presente no documento 294 do livro de foros, editado por A. H. de Oliveira Marques como livro I de sua Chancelaria. No entanto, não é só a clérigos individuais que o rei concede estas desamortizações, mas também igrejas paroquiais, representadas pelas colegiadas, lhe pedem que levante a lei sobre eles, conforme podemos ver abaixo:

Dom Affonso pela graça de Deus Rey de Portugal e do Algarve. A quantos esta carta uiren faço saber que os clérigos de Sancta Maria. De Maruilla de Sanctaren me disseron que a dicta igreja ha em no meu Reguenngo de ualladaxv. Astijsderdade pela qual herdade dizen que se ha de manteer huua capella da dicta egreja e que se an de ffazer per Ella Aniuerssayros pollas almas daqueles que a leixaron aa dicta igreja da qual erdadedizen que pagaron a mjn e aos meus Antecessores os derectos que endeaujan dauer e pediron $\mathrm{mj}$ por mercee que $\mathrm{mj}$ prouguesse de a teeren. $\mathrm{E}$ eu ueendo o que mj pedian e querendo fazer graça e mercee a dicta egreja e a eles. Tenho por bem e mando que ela tenha e aia a dicta herdade no dicto meu Regueengo enquanto for mjnha mercee e que paguen a mjn e aos meus suscessores os derectos e foros que endedeue de pagar. $E$ fazendo o assi mando que nenhuulhj non embargue a dicta herdade em quanto tempo for mha mercee como dicto e. E estolhj faço de graça. Em testeuynho desto Ihj dej esta mha carta. Dante em Sanctarendous dias de Março . El Rej o mandou per Affonso esteuez Francisco Lourenço a fez. Era. M. iij. LXXiij. Anos. Affonso estevez auyo. (Chancelarias portuguesas: Reinado de $D$ Afonso IV, Livro I, Livro de foros, documento 366)

Mais uma vez, D. Afonso IV aquiesce e acolhe o pedido dos clérigos, aceitando que estes possam ter o controle da herdade por tanto tempo quanto ele, 
Revista da Seção Judiciária do Rio de Janeiro

rei de Portugal, entenda ser para o bem comum. Neste caso específico, podemos dizer que o rei "Bravo" optou por seguir os desejos dos clérigos por uma questão de bem comum sobrenatural. Ora, os padres dizem, expressamente, que todos os dias celebram missas pelas almas daqueles que mandaram construir a igreja. Almas estas pertencentes aos súditos de D. Afonso IV e de seus antecessores. Como o próprio rei admite em sua legislação, no fólio 264 verso das Ordenações Del-Rei Dom Duarte, é seu dever contribuir para que seja feita a vontade de Deus na Terra, para que a lei Dele seja mantida e para que as almas de seu reino sejam salvas.

Portanto, nada mais justo do que deixar que clérigos devotos e pios que desejam rezar pelas almas dos mortos o façam, ao menos até que ele, o rei, ache válido. Ao longo da vida, como todo rei medieval e como de praxe em realidade nas monarquias ocidentais, D. Afonso IV dará várias mostras da sinceridade da sua religião cristã católica, fazendo doações ao arcebispado de Lisboa devido a sua devoção à Virgem Maria e a São Vicente, patrono daquela cidade, como se pode ver no documento 12 do segundo livro de sua chancelaria e, ao final da vida, ao deixar explícito em seu testamento seu desejo de construir um hospital para pobres e doentes de Lisboa ${ }^{27}$ e seu pedido para que os padres da Sé de Lisboa, cidade com a qual parecia ter a maior afinidade, rezassem por sua alma e a de sua esposa, a rainha D. Beatriz, a quem parecia ser bem ligado até o Juízo Final.

Ainda assim, o rei Bravo não se limita apenas a estes casos e, em seus livros de chancelaria, também se encontra ao menos ainda dois outros casos de desamortização. Em um deles, monjas pedem que renove a graça já concedida por seu pai, que as liberava de cumprirem estas leis. No outro, decidiu que uma igreja de Melgaço podia também ver suas obrigações de não terem herdades suspensas, uma vez que pagava, como o concelho, direitos ao rei. Vejamos cada um dos documentos e o que podemos extrair deles. Começando pelo caso das monjas:

27 MOTA, António Brochado da. Testamentos Régios - Primeira Dinastia: (1109-1383). 2011. Dissertação (Mestrado em História Medieval) - Faculdade de Letras, Universidade de Lisboa, Lisboa, 2011. Disponível em: http://hdl.handle.net/10451/6784. Acesso em: 30 nov. 2021. p. 92-109. 
DOn Affonso pela graça de Deus Rei de Portugal e do Algarve. A quantos esta carta uiren faço saber que a abadessa e o convento < do moensteiro $>d$ almoester/mi mostraronhua carta $\mathrm{d}$ el Rei Dom Dinis meu padre a que deus perdoe na qual era conteudo que el querendo fazer mercee aa dicta abadessa e conuento desse Moesteiro tinha por bem e mandaua que esse Monsteiro podesse auer todo los herdamentos e [possi]ssões que hileixassen as donas que em esse Moensteiro entrassen em orden Outrossi alguus herdamentos se Ihos alguen leixasse por sas almas. E eu quando fiz cortes em Euora os procuradores que hjueeron das Cidades e das vilas dos meus Reinos que era granmengua e gran despovoamento da mha terra $d$ aueren de guaanharen os moesteiros e as egrejas e as ordiijsherdamentos e possissõesassi como as auyan e guaanhauan e que mjpedian por mercee que esto que o non sofresse e que mandasse aguardar a lei que el Rei meu padre sob estofezera. E eu ueendo que me pedian aguisado mandei e outorguei que essa lei fosse manteuda e aguardada assi em como a meu padre fezera. Pero eu querendo fazer graça e mercee a <e>ssa abadessa e conuen todo dicto Moensteiro porque soube que esse Moensteiro era pobre Tenho por bem e mando que as donas que ora hison ou despois entrarem em esse Monsteiro em ordjn que possan leixar tantos herdamentos de sseus patrimonyos per que esse Monsteiro possa auer mil libras de Renda en cadahuu ano. mais ca o que ora há. Em esto non ser fectonenhuu engano nem cousa a que eu despois aa de tornar. E non lhis seian enbargados pola lei dicta que diz que Moensteiros e egrejas e ordijs non possan auer nen guaanhar nenhuua possissões nen herdamentos. $E$ des que o dicto Moensteiro estou ouuer non auer nen guaanhar mais. E pera ser de <esto certo $>$ mando que as possissões que Moensteiro daqui adeanteouuer ou guaanhar per esta maneira que o faça saber aos tabeliões das Terras hu essas. possissões foren e as façan Registar em seus liuros. Outrossi mando que esta carta seia publicada e registada na audiença dos tabeliões de Sanctaren. E outrossique o escriuan do meu Almoxarifado dessa uila o Registre no liuro do estado do almoxarifado. E mando a essa abadessa ou a outra qualquer que for em esse Moensteiro . e a esse conuento que tanto que Ihis Alguus herdamentos ficarem per esta guisa dessas donas que foren em esse Moensteiro como dicto e que logo o façan saber ao meu almoxarife de Sanctaren e ao meu escriuan pera os escreueren em esse livro E pera o saber. Eu quando esse Moensteiro ouuer acabado a renda das dictas mil libras de que Ihisfaçan graça que esse Moensteiro possa auer E sse assi o non fezeren esta graça non Ihisualha. $E$ as dictas abadessa e conuento tenha essa carta. Dante em tooresuedras trijnta dias de mayo. El Rey o mandou per Johan uicente seu clerigoSteuanperez. a ffez. Era M.iijc e Ix. Quatro. Anos. Johan uicente. (Chancelarias Portuguesas: Reinado de D. Afonso IV, Livro I, documento 74)

Este documento nos demonstra muito bem a atividade do rei "Bravo". Nele, ao levantar a lei de desamortização sobre as supracitadas monjas, D. Afonso IV defende que - apesar do pedido dos procuradores dos concelhos para continuar 
Revista da Seção Judiciária do Rio de Janeiro

aplicando a mesma lei, como o mesmo documento cita - o está fazendo devido à pobreza enorme delas. $\mathrm{O}$ rei baseia-se na ideia de que, embora ele faça as leis e as deva seguir, ele tem o direito de não fazê-lo, caso acredite ser melhor o não cumprimento destas para o bem-comum. Deste modo, o rei de Portugal segue o adágio típico do direito e dos debates intelectuais políticos medievais a partir do século XIII que defendiam que o rei estava, ao mesmo tempo, infra e supra legem, ou seja, abaixo e acima das leis, dependendo da situação como bem demonstrou Kantorowicz em sua obra clássica, Os Dois Corpos do Rei28.

No contexto português, como já demonstraram historiadores brasileiros e como já notamos acima, o uso do termo 'mercê' ou 'graça' sinalizava justamente esta abertura de exceção em casos que o rei julgasse válidos ${ }^{29}$. Isto podia ser usado para cartas de remissão, como Gonçalves destacou, mas também para casos como o das monjas. Neste caso se justifica a não prática da lei como algo afeito ao bem comum, pois o bem comum é não só a Salvação das almas, mas também o aumento da prosperidade, como bem o rei D. Afonso IV demonstra em suas outras leis, recolhidas nas já citadas Ordenações Del-Rei D. Duarte, em seus fólios 286 e 287, verso.

Passemos agora ao caso da igreja no concelho de Melgaço:

Dom Affonso pela graça de Deus Rej de Portugal e do Algarve. A quantos esta carta uiren faço saber que o priol de paderne $m$ enuiou dizer que os concelhos de monçon e de melgaço me dan em cada huu ano setecentes libras de foro e que el paga com os dictos concelhos no dicto foro polas herdades foreyras que hj há. $E$ enuioumj. pedir por mercee que poyselpagaua o dicto foro polasdictas herdades como dictohe que lhj non embargasse essas herdades per razon da lej que foj posta per Rej Dom Afonso meu auoo e per meu padre em que he defeso que clérigos nen ordijs nen ffidallguos non conpren nen guanhen herdades nen possijssões nos regeengosnen foreiras e se as conpraren ou guaanharen que as percam. $\mathrm{E}$ eu querendo Ihis fazer mercee tenho por bem que el aia as dictas herdades assi como as ouue ata aqui. $E$ mando que nenhuu nos lhas embargue

\footnotetext{
${ }^{28}$ KANTOROWICZ, Ernst H. The King's two bodies: A study in medieval political theology. Princeton: Princeton University Press, 2010.

${ }^{29}$ GONÇALVES, Beatris dos Santos. Nas Margens do Reino: Marginalidade, Justiça e Relações de Poder na Baixa Idade Média Portuguesa. Curitiba, Editora Appris, 2018. p. 285-325.
} 
Revista da Seção Judiciária do Rio de Janeiro

quanto he per esta Razon fazendo el a mjn das dictas herdades aqueles foros e derectos que deuen fazer assi como cafdahuu dos outros vizynhos e moradores das dictas uillas como dicto he. E estolhj faço de graça enquanto for mha mercee. Em testemuynho desto Ihj dei esta mjnha carta. Dante em Sancatarem quatro dias de Março. El Rej o mandou per Afonso esteuez e per airaseannesouujdores dos seus fectos Johan lopiz a fez. Era M. iijCLxxij. Anos. (Chancelarias Portuguesas: Reinado de D. Afonso IV, Livro I, documento 350, pp 361 e 362)

D. Afonso IV considera que é bom e justo levantar a lei de desamortização de uma igreja presente num dos ou entre os concelhos de Monção e Melgaço, que paga com estes os direitos régios em formato de dinheiro. Neste caso, o rei não considera que o mais importante seja dominar a terra em si, mas ter acesso aos seus direitos. Se a igreja assim o faz, ele, então, não vê problema no fato de os membros desta colegiada terem acesso à terra. Inclusive parece ser esta sua política geral em relação a este ponto, já que mais adiante vemos que D. Afonso fez o mesmo com, pelo menos, a igreja de São Tomé de Lougares, como consta no documento 351 do livro primeiro de sua chancelaria, e o mosteiro de Fayãaes, como consta no documento seguinte neste mesmo volume. Por sua vez, isto geraria o descontentamento da parte dos concelhos, que, como o próprio rei cita, eram defensores de primeira linha das leis de desamortização.

A atitude do rei nos demonstra um Portugal mais urbano, mais conectado com o mundo ao seu redor, no qual o dinheiro passa a ser tão importante quanto o domínio da terra em si. Na Europa como um todo ${ }^{30}$, os tempos do feudalismo puramente baseado na terra acabaram. Ter acesso ao metal precioso se tornou mais fácil e, desta forma, este recupera seu valor. Assim sendo, não importava ao rei como ele teria acesso aos recursos necessários para o governo da monarquia, contanto que ele os tivesse. Diferentes tipos de acomodação são possíveis.

Até aqui, realizamos uma análise dos casos individuais de desamortização e da motivação do rei para a suspensão da lei em cada um deles, sempre quando estes nos deram elementos para tanto. Haveria, porém, uma razão maior que levaria

${ }^{30}$ Ibid., p. 259-263.

Revista Auditorium, Rio de Janeiro, v. 25, n. 53, p. 104-130, nov. 2021/fev. 2022 
Revista da Seção Judiciária do Rio de Janeiro

D. Afonso IV a ser tão pródigo na abertura de exceções à prática das leis de desamortização? Haveria uma política e um estilo de governo diferenciado de sua parte para justificar esta atitude de modo a compreendermos estes casos como um conjunto indicando o desejo de consolidar uma determinada visão de monarquia? É isto que responderemos a seguir.

\section{D. AFONSO IV E A CONCEITUAÇÃO JURÍDICA E SIMBÓLICA DA MONARQUIA}

Ao iniciarmos este excurso pela maneira como o rei D. Afonso IV optou por aplicar, de acordo com o observado em suas chancelarias, as leis de desamortização criadas por seu pai, discorremos um pouco sobre o estado do reino de Portugal quando este assumiu a coroa em 1325. Citamos a formação da Universidade e da Marinha, o crescimento de cidades como Lisboa e o aumento do comércio de longo alcance. Tratava-se de um Portugal renovado após mais de cinquenta anos de relativa paz e prosperidade e totalmente inserido no contexto europeu de então, muito graças aos reinados de seu avô, D. Afonso III (1248-1279), alcunhado de o "Bolonhês ${ }^{31 "}$, e o de seu já citado pai, D. Dinis (1279-1325), alcunhado de "Rei-Lavrador" ou "Rei-Poeta".

Esta digressão faz-se necessária, pois é graças a ela que entendemos algo fundamental: D. Afonso IV foi, indubitavelmente, o continuador de D. Dinis em muitas atitudes, como demonstrou Carvalho Homem, mas também foi justamente por ser homem de dois séculos e herdeiro de todos estes desenvolvimentos, um homem original, um rei original. Em seu tempo, verdadeiramente, deita raízes de um modo conceitual, baseado no jurídico e no simbólico, qual é a função da monarquia e do governo monárquico, o que acarreta ao rei ser efetivamente um enviado de Deus para junto de seu povo, como os medievais defendiam e sinceramente acreditavam, seja em seus manuais de doutrina política e em seus gestos como demonstrou

${ }^{31}$ VENTURA, op. cit., 2009. 
Revista da Seção Judiciária do Rio de Janeiro

belamente Kantorowicz ${ }^{32}$, seja na psicologia e também nos seus gestos, como demonstrou Marc Bloch ${ }^{33}$. De fato, é verdade que as bases de um Estado Português com o estabelecimento da paz interna necessária para germinar e com a criação de instituições que ficassem para posteridade começaram com os seus dois monarcas antecessores. No entanto, com D. Afonso IV, de modo claro, estabelece os objetivos para esta mesma posteridade do governo e do Estado e a principal ferramenta para se alcançar isto: a lei.

D. Afonso IV não foi o primeiro rei a se reunir em torno de juristas, como demonstraram Armando Luís Carvalho Homem $^{34}$ e Leontina Ventura ${ }^{35}$. Também seu pai e seu avô o fizeram, mas foi em sua época que tal aliança deu resultados não só práticos, no sentido de confecção de leis, como também teóricos, no sentido de justamente demonstrar e enunciar um sentido e um conteúdo para a ação régia que, se antes existia, nunca fora explicitado. A nosso ver, isto é fruto justamente destas heranças e desta integração entre Portugal e Europa. Com efeito, a partir da metade do século XIII, sobretudo a partir da vida de Cino de Pistóia (1270-1336), o estudo do Direito entrou numa nova fase, conhecida como a dos comentadores.

Este novo capítulo da história do direito medieval proporcionou aos juristas não mais apenas descreverem o renascido direito romano como haviam feito até então, mas também buscarem novas soluções a partir dele e, efetivamente, teorizarem sobre como a sociedade deveria ser regida a partir dele, considerando ainda - é claro - o cadinho cristão e teológico que moldava a visão da sociedade na época ${ }^{36}$.

Defendemos que esta escola também esteve presente em Portugal e nele deitou raízes, sobretudo no período aqui delimitado, tendo sido patrocinada por este

\footnotetext{
32 Ibid.

${ }^{33} \mathrm{BLOCH}$, Marc. Os Reis Taumaturgos: $\mathrm{O}$ caráter sobrenatural do poder régio França e Inglaterra. São Paulo: Companhia das Letras, 2019.

${ }^{34}$ Idem.

${ }^{35}$ Ibid.

${ }^{36}$ GILISSEN, John. Introdução Histórica ao Direito. Lisboa: Fundação Calouste Gulbenkian, 2016; HESPANHA, António Manuel. Cultura Jurídica Européia: síntese de um milênio. Florianópolis: Fundação Boiteux, 2009.
} 
Revista da Seção Judiciária do Rio de Janeiro

mesmo rei, D. Afonso IV, o que favoreceu esta conceitualização da monarquia por ele. Para começar, já Martim de Albuquerque, em sua introdução histórica às Ordenações Del-Rei Dom Duarte, demonstra como parte desta extensa recolha de leis - do fólio 365 ao 392 - seria, na verdade, uma aula na Universidade portuguesa contemporânea a Afonso IV, algo que está presente nas páginas XX-XXVI, ministrada por um dos seus legistas mais leais, Estêvão Gomes, e citando dentre outros Cino de Pistóia, justamente. Do mesmo modo, sabemos que, ao longo dos séculos XIV e XV, intensificou-se a ida de estudantes portugueses à Itália com o objetivo de estudar Direito ${ }^{37}$. Ora, a Itália da época era o principal centro de estudo dos comentadores, o que significa que, lá, eles certamente adquiriram a doutrina, retornando com este conhecimento para o reino. Em tempo, isto fez com que sua presença se fizesse sentir também a partir das instituições de ensino do próprio país, ainda mais se considerarmos que uma grande parte destes estudantes retornava para o reino após a conclusão de seus estudos.

Então, a partir das leis formuladas - sem dúvida alguma - como conselho destes juristas, o rei demonstrará efetivamente o papel que a monarquia deve exercer na sociedade, modificando-a de uma instituição sobretudo feudal e já com aspectos de público em uma instituição sobretudo pública e ainda com aspectos feudais, mesmo que importantes. Sobretudo pública, pois se baseia de um modo não mais vago, mas sim bem claro na noção de bem-comum e, inclusive, pretende que os demais súditos, sobretudo os maiores, compreendam esta mudança. Pública, pois busca frequentemente o apoio destes mesmos súditos, através da enunciação do poder monárquico, como se fosse, também, uma propaganda buscando construir um consenso $0^{38}$ e através da reunião dos estados do reino $0^{39}$ - práticas comuns dos Estados em formação, segundo Bernard Guenée. Pública, pois, de algum modo, tenta

${ }^{37}$ LEITÃO OLIVEIRA, de. André. Leges et canones: Portuguese law students in $14^{\text {th }}$ and $15^{\text {th }}$ century Italy. Methodological horizons and problems. In: VASCONCELOS VILAR, Hermínia; BRANCO, Maria João (orgs.). Ecclesiastics and political state building in the Iberian monarchies, 13th -15th centuries. Lisboa: Publicações do Cidehus, 2016.

${ }^{38}$ Ibid., p. 85-93.

${ }^{39}$ Ibid., p. 244-261. 
Revista da Seção Judiciária do Rio de Janeiro

regulamentar os oficiais surgidos nos reinados anteriores e um de seus principais legados, ao mesmo tempo em que cria novos como constatamos nos fólios 317 ao 327 das Ordenações Del-Rei D. Duarte. Feudal ainda, é verdade, devido ao apoio ainda necessário dos nobres terratenentes, ao lado de todas estas mudanças, embora também busque minimamente controlá-los. Se até a época de D. Afonso IV, no entanto, ao se revoltarem, estes nobres desejavam parar o avanço da atividade centralizadora régia, como defende José Mattoso ${ }^{40}$, a partir do fim de seu reinado, de acordo com a leitura de Vasconcelos e Sousa, parece-nos que eles se revoltaram para tomar o controle e as rédeas desta centralização, deste Estado, ao menos até os tempos de Alfarrobeira e do ressurgimento senhorial, como coloca Manuela Mendonça ${ }^{41}$.

Vejamos, agora, a partir do primeiro conjunto de leis promulgado por D. Afonso IV, como ele enunciava e entendia o sentido da ação monárquica que iniciava uma conceitualização clara desta atividade nos corações dos súditos:

Os Reis sam postos cada huum em seu rregno em lugar de deus sobre sasJentes pera as manter em Justiça $\mathrm{E}$ com uerdade $\mathrm{E}$ dar a cada huum seu direito $E$ poremfoy chamado alma $E$ coraçom de seu poboocaassy como a alma Jaz no coraçom do homem $E$ per ellaujue o corpo $E$ se mantem assyel Rey Jaz $\mathrm{E}$ deue Jazer de rrazom $\mathrm{E}$ direita Justiça que heuyda $\mathrm{E}$ mantijmento do poboo e do seu rregno. E como o coraçomhehuum $E$ por ellReçebem todo-llos membros unjdade pera ser huum corpo $E$ bem assy todo-llos do rregno pero sejam mujtos porque el Rey hehuum que deue fazer Justiça $\mathrm{E}$ em ell Jaz deuem ser huus com elldessy porque he cabeça do seu Regno./ Ca assy como da cabeça naçeem os sentidos per que se mandam todo-llos membros do corpo./ assypollo mandamento que naçedel Rey que he cabeça de todo-llos de seu Regno. se deuem mandar E guiar E auerhuum acordo $E$ pera lhe emparar $E$ guardar $E$ endereçar o rregno onde ellhe alma $E$ cabeça E membros por esso há mester que o Rey quando quiser auer acordo sobre alguas cousas que elldeue fazer ou hordenar que ponha higramfemença com aquello que deue $E$ o faça $E$ hordene com sisso $E$ com rrecado $E$ pera esto levar hordenadamente $\mathrm{E}$ o fazer por esta maneira./Primeiramente conuem que hordene $\mathrm{E}$ ponha em rrecado aquello que a ell primeiramente pertence. Assy como sa corte que he com elhua coussa porque he cabeça E cima de toda-llas Justiças de seu Regno E porque he lugar hu todos ham de vijt demandar $E$ pedir direito $E$ os agrauamentos que pollas outras partes do rregno alguns Reçeben en ella ham de ser correJidos $E$ do bem que se

\footnotetext{
${ }^{40}$ Ibid.

${ }^{41}$ MENDONÇA, Manuela. D. João II. Lisboa: Editorial Estampa, 1995.
} 
Revista da Seção Judiciária do Rio de Janeiro

\begin{abstract}
hifezer os outros do rregno dela ham de filhar enxenplo pera fazer direito $\mathrm{E}$ Justiça $E$ os do rregno que das outras terras hiueeremaJam dela boa fama e dem dela boolouuor $E O$ al do rregnonom poderia bem Regido nem bem hordenado ser se a corte del Rey nom fosse E porque ellahe fonte de que naçeem $E$ hi se emçarram todo-llos comprimentos de direito e de Justiça $E$ os do rregno $E$ os das outras terras hiueem pedir $E$ demandar e hideuem de curar de todo-llos feitos da terra(...) (Ordenações Del-Rei Dom Duarte, fls $174 v$ a 175$)$.
\end{abstract}

Assim, o rei de Portugal pretende esclarecer que o objetivo de sua monarquia e de seu Estado não é apenas governar, pois Deus assim quis; afinal, todos os seus antecessores defendem e realmente acreditam que o poder vem de Deus, como observamos nas ordenações que recolheram leis de seu avô, D. Afonso III, e de seu pai, D. Dinis. Mas, sim, governar para atingir a justiça. Foi este, como textualmente ordena que registrem, o objetivo de Deus ao criar os monarcas: garantir que estes realizassem a justiça na Terra e que, dessa maneira, contribuíssem para que Seus filhos, Sua criação humana, dentro da lógica cristã, tivessem tanto uma boa vida material quanto alcançassem, com a ajuda do governo real concomitante às práticas da Igreja, a Salvação eterna. Assim, é justo que o rei possa legislar por eles e fazer com que seu aparato estatal julgue todos os casos do reino mesmo quando envolvam grandes e poderosos, como os nobres e os prelados. Da mesma maneira, é justo que a sociedade do reino busque esta justiça régia, que seja respeitada pelo rei e que presencie sua prática da mercê quando for mais condizente - ao menos em teoria - a estes objetivos e a esta ideia de bem-comum, que, às vezes, justifica a exceção da lei como no caso das leis de desamortização.

\title{
5 CONSIDERAÇÕES FINAIS
}

Através deste duplo jogo - de um lado, arrogar-se como o símbolo máximo da justiça no seu reino, garantindo o bem comum, e, de outro, buscar ser sempre respeitoso aos súditos -, Afonso IV vai construindo uma nova legitimidade para o poder régio, que não parte apenas do relacionamento com os grandes e os poderes 
Revista da Seção Judiciária do Rio de Janeiro

territorializados do reino com o rei agindo como árbitro entre eles, como até então havia sido, mas também, e cada vez mais, de uma noção de uma monarquia e de um Estado público, centrados na prática de um Direito que não só copia o já dito pelo direito romano, como até então se fizera, mas também que busca se manter fiel ante a um sentido geral dos objetivos do poder, o que pode justificar sua alteração ou a não aplicação de leis em determinados contextos.

Esta noção da monarquia como a guardiã do bem-comum da sociedade do reino em sua totalidade só será acentuada nos reinados seguintes até alcançar os tempos de seu tataraneto, D. João II, que a levará ainda a novos degraus com a criação de um novo Hospital em Lisboa e a adoção do Pelicano Eucarístico como sua heráldica ${ }^{42}$, como bem notaram Manuela Mendonça e Priscila Aquino ${ }^{43}$.

Portanto, dentre outros canais, o Estado em Portugal se faz através dessa busca constante de sentido maior de conceitualização da monarquia, que, simultaneamente, reflete os interesses da sociedade e o seu universo naquele momento e que a modela também através dos interesses dos reis, como D. Afonso IV. Através de seus monarcas, a monarquia vai criando uma rede conceitual repleta de significados, sem as quais o Estado não pode nem operar nem ser respeitado, seja pelos grandes, seja pelos nobres, seja pelos grandes prelados, seja pelo clero em geral, seja pelo povo comum.

\footnotetext{
${ }^{42}$ Ibid.

${ }^{43}$ AQUINO, Priscila. Entre Príncipe perfeito e Rei Pelicano: Os caminhos da memória e da propaganda política através do estudo da imagem de D. João II (Século XV). 2007. Dissertação (Mestrado em História), Institutos de Ciências Humanas e Sociais - Universidade Federal Fluminense, Niterói, 2007. Disponível em: https://app.uff.br/riuff/handle/1/18808. Acesso em: 2 dez. 2021.
} 
Revista da Seção Judiciária do Rio de Janeiro

\section{REFERÊNCIAS}

\section{Fontes}

ALBUQUERQUE, Martim de; NUNES, Eduardo Borges (org.). Ordenações Del-Rei Dom Duarte. Lisboa: Fundação Calouste Gulbenkian, 1988.

OLIVEIRA MARQUES, de. A. H (org.). Chancelarias portuguesas: Reinado de D. Afonso IV, 1325-1336. Lisboa: Instituto Nacional de Investigação científica/Centro de estudos históricos da Universidade Nova de Lisboa, 1990. vol. 1.

\section{Bibliografia}

ALBUQUERQUE, Martim. Introdução. In: ALBUQUERQUE, Martim; NUNES, Eduardo. Ordenações Del-Rei Dom Duarte. Lisboa. Fundação Calouste Gulbenkian, 1988.

AQUINO, Priscila. Entre Príncipe perfeito e Rei Pelicano: Os caminhos da memória e da propaganda política através do estudo da imagem de D. João II (Século XV). 2007. Dissertação (Mestrado em História), Institutos de Ciências Humanas e Sociais - Universidade Federal Fluminense, Niterói, 2007. Disponível em: https://app.uff.br/riuff/handle/1/18808. Acesso em: 2 dez. 2021.

ARAÚJO, Julieta. D. Afonso IV. In: MENDONÇA, Manuela. História dos Reis de Portugal: Da fundação à perda da Independência. Lisboa: Edições Quidnovi, 2010, p. 299-341. vol. 1.

BARROS, José d'Assunção. História política: da expansão conceitual às novas conexões intradisciplinares. Revista OPSIS, Goiânia, v. 12, n. 1, p. 29-55, jan./jun. 2012. Disponível em: https://revistas.ufg.br/Opsis/article/view/17338. Acesso em: 2 dez. 2021.

BASCHET, Jérôme. Primeira Parte: Formação e desenvolvimento da Cristandade feudal - Da Europa Medieval à América Colonial. In: BASCHET, Jérôme. A

Civilização Feudal: Do ano mil à Colonização da América. São Paulo: Editora Globo, 2005. p. 247-274.

BLOCH, Marc. Os Reis Taumaturgos: O caráter sobrenatural do poder régio França e Inglaterra. São Paulo: Companhia das Letras, 2019.

BOEHNER, Philotheus; GILSON, Étienne. História da Filosofia Cristã. Petrópolis: Editora Vozes, 2017. 
Revista da Seção Judiciária do Rio de Janeiro

BOWSKY, William. A Mediaeval Italian Commune: Siena under the Nine, 1287-1355. Berkeley: University of California Press, 1981.

CARDOSO, Ciro Flamarion; VAINFAS, Ronaldo. História e análise de textos. In: CARDOSO, Ciro Flamarion; VAINFAS, Ronaldo (org.). Domínios da História: Ensaios de teoria e metodologia. Rio de Janeiro: Editora Campus, 1997. p. 536-567.

HOMEM, Luís Armando Carvalho. O Desembargo Régio (1320-1433). 1985. Tese (Doutorado em História da Idade Média) - Faculdade de Letras, Universidade do Porto, Porto, 1985. Disponível em: https://repositorio-aberto.up.pt/handle/10216/13225. Acesso em: 1 dez. 2021.

HOMEM, Luís Armando Carvalho. Dionisus et Alfonsus, Dei Gratia Reges et communis utilitatis Gratia legiferi. Revista de História da Faculdade de Letras da Universidade do Porto, Porto, v. 11, p. 11-111, 1994. Disponível em: https://ojs.letras.up.pt/index.php/historia/article/view/5660. Acesso em: 1 dez. 2021.

FOSSIER, Arnaud-Vivien. La Pénitencerie pontificale en Avignon (XIV siècle) ou la justice des âmes comme style de gouvernement. Les Justices d'Église dans le Midi (XI-XV siècles): 42éme colloque de Fanjeaux, Fanjeaux, p. 199-240, jul. 2006. Disponível em: https://halshs.archives-ouvertes.fr/halshs-00369875. Acesso em: 30 nov. 2021.

GÉNICOT, Léopold. Le XIII ${ }^{\mathbf{e}}$ siècle Européen. Paris: Presse Universitaire de France, 1984.

GILISSEN, John. Introdução Histórica ao Direito. Lisboa: Fundação Calouste Gulbenkian, 2016.

GONÇALVES, Beatris dos Santos. Nas Margens do Reino: Marginalidade, Justiça e Relações de Poder na Baixa Idade Média Portuguesa. Curitiba, Editora Appris, 2018.

GUENÉE, Bernard. L'Ocident aux XIV et XV siècles: Les États. Paris: Presse Universitaire de France, 1971.

HARDING, Alan. Medieval Law and the foundation of the State. Oxford: Oxford University Press, 2005.

HESPANHA, António Manuel. Cultura Jurídica Européia: síntese de um milênio. Florianópolis: Fundação Boiteux, 2009.

HUIZINGA, Johan. O Outono da Idade Média. São Paulo: Cosac \& Naify Editora, 2010. 
Revista da Seção Judiciária do Rio de Janeiro

KANTOROWICZ, Ernst $\mathrm{H}$. The King's two bodies: A study in medieval political theology. Princeton: Princeton University Press, 2010.

LE GOFF, Jacques. Seria o político ainda a ossatura da História? In: LE GOFF, Jacques. 0 maravilhoso e o quotidiano na Idade Média. Lisboa: edições 70, 1981. p. 221-243.

LEITÃO OLIVEIRA, de. André. Leges et canones: Portuguese law students in $14^{\text {th }}$ and $15^{\text {th }}$ century Italy. Methodological horizons and problems. In: VASCONCELOS VILAR, Hermínia; BRANCO, Maria João (orgs.). Ecclesiastics and political state building in the Iberian monarchies, 13th -15th centuries. Lisboa: Publicações do Cidehus, 2016.

MATTOSO, José (org.). História de Portugal: A Monarquia Feudal 1096-1480. Lisboa: Editorial Estampa, 1997. vol. 2.

MATTOSO, José. Identificação de um país: Ensaio sobre as origens de Portugal (1096-1325) - Oposição/Composição. Lisboa: Editora Temas e Debates, 2016.

MENDONÇA, Manuela. D. João II. Lisboa: Editorial Estampa, 1995.

MENEZES LUIZ, Láisson. As Concordatas: abusos e violências cometidas contra os clérigos em Portugal ao tempo de D. Dinis. Revista Sapiência: Sociedades, Saberes e Práticas Educacionais, Iporá, v. 1, n. 2, p. 58-72, jul./dez. 2012. Disponível em: https://www.revista.ueg.br/index.php/sapiencia/article/view/2688. Acesso em: 30 nov. 2021.

MOTA, António Brochado da. Testamentos Régios - Primeira Dinastia:

(1109-1383). 2011. Dissertação (Mestrado em História Medieval) - Faculdade de Letras, Universidade de Lisboa, Lisboa, 2011. Disponível em: http://hdl.handle.net/10451/6784. Acesso em: 30 nov. 2021.

NASCIMENTO, Luciana de Araújo; COSTA, Célio Juvenal. A Singularidade da primeira Universidade Portuguesa no contexto do nascimento das universidades medievais.

In: Seminário de Pesquisa do Programa de Pós-Graduação em Educação, Universidade Estadual de Maringá, 2011, Maringá. Anais [...]. Maringá: UEM, 2011. Disponível em:

http://www.ppe.uem.br/publicacoes/seminario_ppe_2011/pdf/4/071.pdf. Acesso em: 2 dez. 2021.

PIZARRO, José Augusto Sotto Mayor. D. Dinis: Um gênio da Política. Lisboa: Temas \& Debates, 2012. 
Revista da Seção Judiciária do Rio de Janeiro

SILVA, José Custódio Vieira da. Lisboa Medieval: Breves Reflexões. Revista História da Arte, n. 2, p. 36-42, 2006. Disponível em: http://hdl.handle.net/10362/12447. Acesso em: 30 nov. 2021.

VASCONCELOS E SOUSA, Bernardo. D. Afonso IV. Lisboa: Temas \& Debates, 2009.

VENTURA, Leontina. D. Afonso III. Lisboa: Editora Temas \& Debates, 2009.

WALEY, Daniel; DENLEY, Peter. Later Medieval Europe: (1250-1520). New York:

Routledge, 2013. 